\title{
PERBAIKAN SISTEM PENGUMPULAN SAMPAH PADA PERUMAHAN DI KOTA BATAM
}

\author{
Welly Sugianto*), Elva Susanti \\ Prodi Teknik Industri, Fakultas Teknik dan Komputer, Universitas Putera Batam, \\ Jl. Letjen. R. Soeprapto, Batam, Indonesia, 29439
}

(Received: October 26, 2017/ Accepted: May 31, 2018)

\begin{abstract}
Abstrak
Proses pengangkutan sampah di kota Batam dilakukan oleh truk pengangkut sampah. Truk pengangkut sampah masuk ke perumahan dan mengambil sampah yang ada di depan setiap rumah warga. Jumlah truk sampah tidak memadai sehingga sampah menumpuk di depan rumah warga. Warga mengambil inisiatif untuk membuang sampah tersebut di sembarang tempat sehingga tercipta TPS liar. Penelitian ini bertujuan untuk mencari jumlah truk pengangkut sampah yang optimum agar tidak terjadi timbunan sampah di depan rumah warga dan mencegah timbulnya TPS liar. Pendekatan yang digunakan adalah teori antrian dengan populasi terbatas. Truk sampah melayani sejumlah rumah dalam satu wilayah. Jumlah rumah dalam satu wilayah bersifat terbatas dan tetap. Rumah ditetapkan sebagai pelanggan jika jumlah sampah yang ada di depan rumah lebih dari 5 kantong atau lebih dari $20 \mathrm{~kg}$. Beberapa data yang akan diobservasi adalah tingkat kedatangan dan kecepatan pelayanan. Berdasarkan data tersebut dapat dihitung beberapa parameter seperti tingkat antrian, waktu objek dalam antrian, probabilitas objek dalam sistem antrian, probabilitas sejumlah objek dalam antrian, dan biaya total yang merupakan penggabungan antara biaya antrian dan biaya operasional. Penelitian ini dilakukan di Kota Batam. Hasil penelitian menunjukkan bahwa teori antrian dengan populasi terbatas dapat diterapkan untuk menghitung jumlah truk pengangkut sampah yang optimum. Implementasi usulan perbaikan berdampak pada peningkatan kecepatan pelayanan dari 267,2 rumah per hari menjadi 480,8 rumah per hari. Jumlah truk yang optimum untuk satu wilayah perumahan setelah implementasi perbaikan adalah 2.
\end{abstract}

Kata kunci: Antrian; Populasi Terbatas; Truk Sampah

\begin{abstract}
[Determination of the Optimal Number of Trucks in the Garbage Transport Process] The garbage collection process in Batam city is carried out by garbage truck. Trucks must enter the housing and take out the garbage that is in front of each house. the number of garbage trucks is not enough so that the garbage overflows in front of the house. Residents took the initiative to dispose of the garbage in any place so as to create illegal polling stations. The objective of this research are to find the optimum garbage truck to avoid garbage pile in front of the residents' house and to prevent the occurrence of illegal polling stations. The approach used is queuing theory with limited population. Garbage trucks serve a number of houses in one area. The number of houses in one area is limited and fixed. The house is designated as a customer if the amount of garbage in front of the house is more than 5 bags or more than $20 \mathrm{~kg}$. Some data to be observed is the arrival rate and speed of service. Some parameters to be calculated are the queue level, the time of the object in the queue, the probability of the object in the queue sistem, the probability of a number of objects in the queue, and the total cost which is a combination of queuing costs and operational costs. This research was conducted in Batam City. The results show that queuing theory with limited population can be applied to calculate the number of optimum garbage trucks. Implementation of the proposed improvements has an impact on the increase of speed of service rate from 267.2 houses per day to 480.8 houses per day. The optimum number of trucks in region after the implementation of the improvement is 2
\end{abstract}

\footnotetext{
*) Penulis Korespondensi.

E-mail: welly@puterabatam.ac.id
}

Keywords: Queue; Finite Population; Garbage truck 


\section{Pendahuluan}

Batam merupakan bagian dari Kepulauan Riau dengan luas wilayah sebesar $1595 \mathrm{Km}^{2}$ dan berpenduduk 1,3 juta jiwa. Sampai saat ini, Batam menghasilkan sampah dengan jumlah 1.184,28 ton per hari. Sampah yang dihasilkan terdiri dari sampah kering dan sampah basah. Sampah tersebut dihasilkan oleh rumah tangga dan industri. Sampah rumah tangga di kota Batam tidak dikumpulkan di tempat penampungan, namun dikumpulkan di depan rumah masing-masing warga. Truk sampah secara periodik berkeliling dan mengambil sampah yang ada di depan rumah warga. Permasalahan yang saat ini terjadi adalah jumlah dan frekuensi kedatangan truk sampah yang tidak konsisten. Frekuensi truk sampah dalam hal mengambil sampah di depan masing-masing rumah warga adalah sekali dalam 2 hari sampai sekali dalam 3 minggu. Hal ini mengakibatkan sampah menumpuk di depan rumah warga. Sampah tersebut menimbulkan bau tidak sedap dan penyakit serta mengganggu pemandangan. Untuk mengatasi hal ini, warga mengambil inisiatif untuk membuang sampah di sembarang tempat sehingga tercipta tempat pembuangan sampah liar. Sampah semakin menumpuk di tempat penampungan sampah liar dan meluber ke tengah jalan. Sampah yang meluber menimbulkan bau tidak sedap, menimbulkan penyakit dan mengganggu keindahan. Permasalahan utama yang dihadapi adalah perhitungan jumlah truk sampah yang masih belum optimal sehingga terjadi penumpukan sampah di depan rumah warga dan TPS. Penelitian ini bertujuan untuk memberikan solusi mengenai jumlah truk pengangkut sampah yang optimum untuk mengangkut sampah dari tiap rumah ke TPA Punggur - Batam dengan pendekatan antrian populasi terbatas.

Pendekatan antrian diimplementasikan pada proses pengangkutan sampah di Pilgrim. Pendekatan antrian yang digunakan adalah multiple service infinite population. Pendekatan tersebut digunakan untuk mengevaluasi seluruh karakteristik antrian pada berbagai kondisi yang disimulasikan. Usulan perbaikan berupa suatu sistem pengangkutan yang mampu mereduksi rata-rata waktu objek dalam sistem antrian (Aradhye \& Kallurkar, 2014).

Pendekatan antrian dengan model M/M/S diimplementasikan untuk mengevaluasi kinerja manajemen sampah di Lawma Igando, Lagos State. Model M/M/S yang digunakan merupakan model antrian dengan populasi yang tidak terbatas. Waktu pelayanan dan waktu antar kedatangan pelanggan berdistribusi eksponensial. Performa antrian yang sedang berjalan digunakan untuk mengestimasi waktu antar kedatangan, waktu pelayanan dan waktu tunggu pelanggan dalam sistem antrian (Paul, Ojekudo, \& Akpofure, 2015).

Logisitik internal manajemen sampah dapat dianalisis dengan pendekatan antrian dengan model M/M/1 di mana distribusi waktu antar kedatangan adalah markovian atau eksponensial, distribusi waktu pelayanan adalah markovian atau eksponensial dan jumlah server sebesar 1. Karakteristik sistem antrian truk pada saat proses pengisian bahan bakar dan proses pengisian sampah dapat dianalisis dengan akurat (Zaveršnik, Tina, Grobin, \& Rosi, 2015).

Pada manajemen sampah, jumlah truk sampah harus ditentukan secara optimal. Salah satu pendekatan yang digunakan adalah algoritma heuristic. Algoritma ini banyak digunakan pada beberapa penelitian untuk menentukan jumlah truk pengangkut sampah yang optimal. Selain jumlah truk sampah yang optimal, hasil penelitian harus memberikan solusi untuk memperbaiki hasil perhitungannya. Salah satu penyebab terjadinya antrian pengangkutan di TPS dan antrian di rumah penduduk adalah waktu istirahat sopir truk pengangkut sampah yang tidak diatur dengan baik sehingga menimbulkan antrian yang panjang dan meningkatkan rata-rata waktu pelayanan dan rata-rata waktu pelanggan dalam sistem (Benjamin, KuMahamud, \& Idrus, 2017).

Pengembangan model matematis juga dilakukan pada manajemen sampah di Awka, Negara bagian di Anamba. Kebanyakan manajer pengelola sampah tidak memahami metode yang digunakan untuk menganalisis sistem pengangkutan sampah. Data-data tidak diorganisasikan dengan baik dan tidak dianalisis dengan metode yang memadai. Model matematika perlu dikembangkan berdasarkan situasi yang riil. Pengembangan model matematika tersebut dilakukan berdasarkan teori antrian namun disesuaikan dengan kondisi yang ada di lapangan. Model matematika tersebut tidak jauh berbeda dengan teori antrian dan hanya merupakan penyederhanaan dari teori antrian agar mudah diaplikasikan orang awam. Model tersebut digunakan untuk mengevaluasi kinerja departemen kebersihan dan untuk menentukan jumlah truk yang optimum serta untuk memberikan saran perbaikan (Chukwumuanya \& Ihueze, 2017).

Kinerja proses pengangkutan sampah dapat dilakukan dengan menggunakan data cycle time. Setiap truk sampah dilengkapi dengan komputer untuk merekam data cycle time. Data cycle time tersebut diolah untuk mengetahui distribusi, variansi, dan nilai pusatnya. Data cycle time tersebut digunakan untuk menghitung jumlah truk sampah. Beberapa faktor lain yang mempengaruhi variansi cycle time adalah model atau tipe truk, model excavator, kondisi jalan, dan tipe material atau tipe sampah (Manyele, 2017).

Selain itu, pemanfaatan teknologi informasi dalam manajemen sampah juga digunakan. Sebagai contoh adalah penerapan sensor pada tempat sampah. Implementasi teknologi informasi cukup bagus namun masih belum dapat memberikan solusi untuk memperbaiki karakteristik antrian proses pengambilan sampah (Lundin, Ozkil, \& Schuldt-Jensen, 2017). Pemanfaatan teknologi informasi yang lain adalah GIS atau Geographic Information Sistem. Peranan GIS dalam manajemen sampah makanan sangat penting dalam aspek perencanaan dan manajemen operasi. GIS juga mengelola data untuk menanalisis lokasi yang optimal untuk $N G O s$, merencanakan rute kendaraan 
yang mengangkut sampah makanan ke tempat pembuangan akhir, merencanakan TPS yang baru dan lain sebagainya. Sensor GIS juga memetakan permukaan bumi secara actual dengan mengintegrasikan beberapa parameter penting (Raut, Nagne, \& Kale, 2015).

Pengelolaan dan penentuan jumlah truk pengangkut sampah di vietnam juga dilakukan dengan menggunakan GPS dan GIS. Indikator penilaian efisiensi yang digunakan adalah waktu operasi, jam kerja, dan kecepatan operasi atau kecepatan pelayanan. Kapasitas pengangkutan sampah dan waktu pelayanan dihitung dengan regresi. Selain itu, analisis sensitivitas juga dilakukan untuk menilai dampak dari jumlah truk, kapasitas truk, frekuensi pengambilan sampah (waktu pelayanan) dan pemisahan sampah organik-anorganik. Frekuensi pengambilan sampah memberikan dampak yang signifikan pada efisiensi pengambilan sampah (NH, Vi, Mai, \& Matsui, 2018).

Peningkatan efektifitas manajemen sampah juga dapat dilakukan melalui pemetaan demografis berdasarkan usia, pekerjaan, gender dan lain sebagainya. Namun cara ini tidak menghitung secara detail karaktersitik proses pengangkutan sampah (Miezah, Obiri-Danso, Kádár, Fei-Baffoe, \& Mensah, 2015). Penentuan jumlah server atau jumlah truk pengangkut sampah juga dapat dilakukan melalui klasifikasi residen atau populasi berdasarkan kelas sosio ekonominya. Populasi dibagi menjadi 3 kelas ekonomi yakni rendah, sedang dan tinggi. Masingmasing kelas ekonomi memengaruhi jenis dan jumlah sampah yang akan dihasilkan (Tambe, Ayongwa, Ngwabie, \& Forbid, 2016).

Analisis menyeluruh dengan menggunakan statistik deskritif yang sederhana dilakukan pada sistem manajemen sampah di kota Delhi. Analisis dilakukan mulai dari proses pengambilan sampah, pengangkutan dan pembuangan sampah. Pertumbuhan populasi penduduk yang tinggi dan pertumbuhan industri memengaruhi kinerja infrastruktur dan pelayanan pengangkutan sampah. Penduduk kota Delhi menghasilkan sampah antara 6.000 sampai 8.000 metrik ton per hari dan naik secara signifikan setiap periode. Hasil analisis menunjukkan bahwa terdapat variasi jumlah sampah yang signifikan di setiap wilayah pada kota Delhi. Hal ini mengakibatkan penurunan kemampuan pengangkutan sampah dan peningkatan penumpukan sampah diberbagai wilayah. Hasil analisis hanya bersifat deskriptif dan tidak menentukan jumlah truk pengangkut sampah yang akurat (Kumar, 2013).

Analisis pengangkutan sampah juga dapat dilakukan berdasarkan pendekatan sistem logistik. Sistem logistik memaksimalkan penggunaan infrastruktur, sumber daya, dan biaya. Sistem logistik tersebut harus mengutamakan aspek teknologi, aspek ekologi dan aspek ekonomi (Marczak, 2016). Simulasi diskrit juga diaplikasikan dalam menilai performansi dan evaluasi kinerja manajemen sampah. Simulasi diskrit juga ditujukan untuk meningkatkan produktivitas dan efisiensi dari manajemen sampah. Simulasi diskrit dilakukan berdasarkan skenario yang nyata seperti arrival times, populasi, perubahan jumlah sampah akibat dari perubahan jumlah populasi, perubahan gaya hidup untuk mulai menggunakan bahan yang dapat didaur ulang, dan lain sebagainya. Simulasi diskrit mampu mendukung kinerja manajemen (Harison, Cherkassky, \& Barkai, 2016).

Penentuan jumlah truk pengangkut sampah atau penentuan jumlah server serta penilaian kinerja karakteristik sistem antrian aktivitas pengangkutan sampah masih belum pernah dilakukan dengan menggunakan pendekatan antrian populasi terbatas. Penelitian ini menentukan jumlah server dan menganalisis kinerja sistem antrian proses pengangkutan sampah dengan menggunakan pendekatan antrian populasi terbatas. Hal ini dilakukan karena pelayanan pengangkutan sampah dilakukan pada sebuah wilayah perumahan dengan jumlah rumah yang tetap sehingga pendekatan antrian yang digunakan adalah antrian dengan populasi terbatas. Penelitian terdahulu masih belum menggunakan pendekatan ini. Wilayah perumahan yang dijadikan objek penelitian adalah perumahan Tembesi, Batu Aji, Kota Batam.

\subsection{Karakteristik Sistem Antrian}

Terdapat 3 komponen dalam karakteristik sistem antrian yakni: kedatangan atau masukan sistem yang meliputi ukuran populasi, perilaku dan distribusinya, antrian atau disiplin antrian yang meliputi jumlah antrian dan materi yang ada dalam antrian dan fasilititas pelayanan yang meliputi desain dan distribusi statistik waktu pelayanan (Heizer \& Render, 2011).

\subsubsection{Karakteristik Kedatangan}

Kedatangan pelanggan memiliki tiga karakteristik utama yaitu ukuran populasi kedatangan, perilaku kedatangan dan pola kedatangan (Heizer \& Render, 2011). Penjelasan masing-masing karakteristik dijabarkan sebagai berikut:

\section{Ukuran Populasi Kedatangan}

Ukuran populasi kedatangan terdiri dari 2 kemungkinan yaitu terbatas dan tidak terbatas. Populasi kedatangan yang tidak terbatas memiliki karakteristik sebagian kecil dari semua kedatangan yang potensial. Populasi yang terbatas adalah sebagian besar dari semua kedatangan yang potensial.

\section{Perilaku Kedatangan}

Asumsi perilaku kedatangan pada sistem antrian adalah bahwa seluruh materi yang ada dalam sistem antrian menunggu untuk dilayani dan materi tersebut tidak berpindah garis antrian. Tidak ada materi yang meninggalkan garis antrian.

\section{Pola Kedatangan}

Asumsi pola kedatangan dianggap acak sehingga antar kedatangan adalah acak dan independen (Sivaraman \& Bharti, 2017). Asumsi pola kedatangan dalam sistem antrian adalah distribusi 
poison. Untuk setiap waktu kedatangan, probabilitas jumlah kedatangan persatuan waktu ditetapkan dengan menggunakan persamaan sebagai berikut:

$$
P(x)=\frac{e^{-\lambda} \lambda^{x}}{x !}
$$

$\lambda$ merupakan kecepatan kedatangan pelanggan.

\subsubsection{Karakteristik Antrian}

Panjang sebuah sistem antrian dapat terbatas atau tidak terbatas. Sistem antrian terbatas merupakan suatu sistem antrian yang jumlah materi dalam antrian tidak dapat meningkat tanpa batas melainkan jumlahnya telah tentu atau telah ditetapkan. Ketetapan jumlah antrian dapat disebabkan oleh karena adanya aturan maupun keterbatasan fisik seperti daya tampung ruang antrian. Sistem antrian tidak terbatas merupakan suatu sistem antrian yang jumlah materi dalam antrian dapat meningkat tanpa batas. Asumsi distribusi waktu antar kedatangan dan waktu pelayanan harus dipenuhi karena persamaan yang digunakan untuk menganalisis antrian tersebut diturunkan berdasarkan distribusi kedua variabel tersebut (Heizer \& Render, 2011).

\subsubsection{Karakteristik Pelayanan}

Distribusi waktu pelayanan berkaitan dengan probabilitas waktu pelayanan (Hillier \& Lieberman, 2015). Jika waktu pelayanan konstan, maka setiap pelanggan akan mendapatkan waktu pelayanan yang sama. Namun tidak semua waktu pelayanan adalah konstan. Jika waktu pelayanan tidak konstan maka probabilitas waktu pelayanan ditunjukkan oleh distribusi probabilitias eksponensial negatif. Pada distribusi probabilitas eksponensial negatif, probabilitas waktu pelayanan yang panjang adalah kecil. Probabilitas waktu pelayanan dihitung dengan menggunakan persamaan berikut:

$$
P(t)=e^{-\mu . t}
$$

$\mu$ adalah waktu pelayanan rata-rata.

\subsection{Kinerja Antrian untuk Populasi Terbatas}

Beberapa parameter yang akan dinilai antara lain adalah probabilitas jumlah objek dalam antrian sebesar nol, probabilitas objek dalam antrian sebesar $\mathrm{n}$, rata-rata jumlah objek dalam antrian, rata-rata jumlah objek dalam sistem, rata-rata kecepatan kedatangan pelanggan, rata-rata waktu objek dalam sistem, dan rata-rata waktu objek dalam antrian (Paul et al., 2015).

\subsection{Optimasi Biaya dalam Model Antrian}

Terdapat beberapa biaya yang muncul dalam suatu sistem antrian, yakni:

1. Biaya tidak langsung yang dihadapi pelanggan yang menunggu dalam antrian atau dalam sistem. Biaya tidak langsung terjadi jika tingkat penggunaan sistem sangat tinggi.

2. Biaya langsung untuk penyediaan fasilitas pelayanan seperti listrik, sewa, biaya karyawan dan lain-lain.
3. Selain itu juga terdapat biaya menunggu yang dapat berupa :

a. Biaya menganggurnya para karyawan

b. Biaya kehilangan pelanggan

c. Biaya persediaan yang berlebihan

d. Biaya kehilangan kontrak

e. Biaya kehilangan kesempatan untuk mendapatkan laba

f. Biaya kemacetan sistem

g. Biaya antrian pelanggan yang sedang menunggu pelayanan seperti fasilitas dan lainlain

h. Biaya kehilangan kepercayaan dari pelanggan.

Biaya menunggu sulit ditentukan. Biaya menunggu dapat berupa biaya dari sistem internal maupun biaya yang berasal dari sistem antrian. Biaya yang berasal dari sistem internal (biaya persediaan atau biaya karyawan menganggur) dapat diukur. Sebagai contoh adalah truk yang sedang menunggu pelayanan bongkar muatan. Biaya antrian yang berasal dari antrian truk antara lain yakni bahan bakar dan tenaga kerja (Heizer \& Render, 2011).

\section{Bahan dan Metode}

\subsection{Kecukupan Jumlah Data}

Perhitungan kecukupan jumlah data kecepatan kedatangan pelanggan dan kecepatan pelayanan dilakukan persamaan rules of thumb (Belle, 2008) dengan persamaan:

$$
n=\frac{4}{\left(\sqrt{\theta_{0}}-\sqrt{\theta_{1}}\right)^{2}}
$$

\subsection{Uji Distribusi Data}

Uji distribusi data dilakukan pada data kecepatan kedatangan pelanggan (yang dalam hal ini adalah pertambahan jumlah rumah yang tempat sampahnya terisi dan pertambahan tersebut dihitung per jam). Uji distribusi data kecepatan pelayanan dan kecepatan kedatangan pelanggan dilakukan dengan menggunakan bantuan minitab.

2.3 Model Matematis Antrian dengan Single Server Model matematis antrian populasi terbatas diturunkan dari birth and death process yang disajikan pada gambar 1 (Hillier \& Lieberman, 2015).

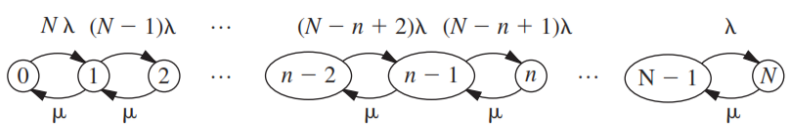

Gambar 1. Birth and death process untuk single server.

Model matematis untuk single server disajikan pada persamaan 4 dan 5 .

$$
\begin{aligned}
& \lambda_{n}= \begin{cases}(N-n) \lambda, & \text { untuk } \mathrm{n}=0,1,2, \ldots ., \mathrm{N} \\
0, & \text { untuk } \mathrm{n} \geq \mathrm{N}\end{cases} \\
& \mu_{n}=\mu, \\
& \text { untuk } \mathrm{n}=1,2, \ldots .
\end{aligned}
$$




$$
\begin{gathered}
C_{n}=\left\{\begin{array}{l}
N(N-1) \cdots(N-n+1)\left(\frac{\lambda}{\mu}\right)^{n}=\frac{N !}{(N-n) !}, \text { untuk } \mathrm{n} \leq \mathrm{N} \\
0, \quad \text { untuk } \mathrm{n} \geq \mathrm{N}
\end{array}\right. \\
P_{n}=C_{n} P_{0}
\end{gathered}
$$

Keterangan :

$\mathrm{N}=$ jumlah populasi dalam satu wilayah perumahan

$\mathrm{n}=$ jumlah objek dalam sistem antrian

$\lambda=$ kecepatan kedatangan pelanggan

$\mu=$ kecepatan pelayanan

$\mathrm{C}_{\mathrm{n}}=$ faktor antrian

$\mathrm{P}_{0}=$ probabilitas jumlah objek dalam antrian sebesar 0

Data yang harus diperoleh adalah kecepatan kedatangan pelanggan per hari dan kecepatan pelayanan per jam. Selanjutnya, rata-rata kecepatan kedatangan pelanggan per hari dan kecepatan pelayanan per jam ditentukan dengan persamaan 7 .

$$
\mu=\frac{\sum_{\mathrm{i}=1}^{\mathrm{n}}\left(\mathrm{x}_{\mathrm{i}} \times \mathrm{f}_{\mathrm{i}}\right)}{\sum_{\mathrm{i}=1}^{\mathrm{n}} \mathrm{f}_{\mathrm{i}}}=\sum_{\mathrm{i}=1}^{\mathrm{n}}\left(\mathrm{x}_{\mathrm{i}} \times \mathrm{P}_{\mathrm{i}}\right)
$$

Keterangan :

$\mathrm{f}=$ frekuensi

$\mathrm{x}=$ kecepatan kedatangan atau kecepatan pelayanan

Berikut ini adalah persamaan-persamaan untuk menganalisis kinerja antrian single server dengan populasi terbatas yang diturunkan dari model matematis (Hillier \& Lieberman, 2015):

a. Probabilitias jumlah objek dalam antrian sebesar nol

$$
P_{0}=\frac{1}{\sum_{n=0}^{N}\left[\frac{N !}{(N-n) !}\left(\frac{\lambda}{\mu}\right)^{n}\right]}
$$

b. Probabilitas objek dalam antrian sebesar $n$ $\left(P_{n}\right)$

$$
P_{n}=\frac{N !}{(N-n) !}\left(\frac{\lambda}{\mu}\right)^{n} P_{0}
$$

c. Rata-rata jumlah objek dalam antrian $\left(\mathrm{L}_{\mathrm{q}}\right)$

$$
L_{q}=\sum_{n=1}^{N}(n-1) P_{n}=N-\frac{\lambda+\mu}{\lambda}\left(1-P_{0}\right)
$$

d. Rata-rata jumlah objek dalam sistem (L)

$$
L=\sum_{n=0}^{N} n P_{n}=N-\frac{\mu}{\lambda}\left(1-P_{0}\right)
$$

e. Rata-rata kecepatan kedatangan pelanggan $(\bar{\lambda}$$$
\bar{\lambda}=\sum_{n=0}^{N} \lambda_{n} P_{n}=\sum_{n=0}^{N}(N-n) \lambda P_{n}=\lambda(N-L)
$$

f. Rata-rata waktu objek dalam sistem (W)

$$
W=\frac{L}{\bar{\lambda}}
$$

g. Rata-rata waktu objek dalam antrian $\left(\mathrm{W}_{\mathrm{q}}\right)$

$$
W_{q}=\frac{L_{q}}{\bar{\lambda}}
$$

2.4 Analisis Karakteristik Antrian Multiple Server.

Model matematis antrian populasi terbatas diturunkan dari birth and death process yang disajikan pada Gambar 2 (Hillier \& Lieberman, 2015).
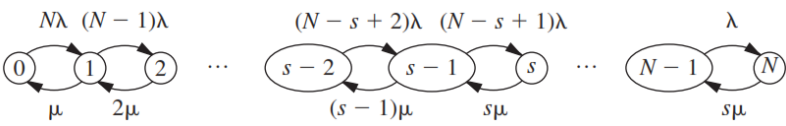

Gambar 2. Birth and Death Process untuk Multiple Server.

Model matematis untuk single server diturunkan dari birth and death prosess dan disajikan pada persamaan 15 dan 16.

$$
\begin{gathered}
\lambda_{n}= \begin{cases}(N-n) \lambda, & \text { untuk } \mathrm{n}=0,1,2, \ldots ., \mathrm{N} \\
0, & \text { untuk } \mathrm{n} \geq \mathrm{N}\end{cases} \\
\mu_{n}= \begin{cases}n \mu, & \text { untuk } \mathrm{n}=1,2, \ldots, \mathrm{s} \\
s \mu, & \text { untuk } \mathrm{n}=\mathrm{s}, \mathrm{s}+1, \mathrm{~s}+2, \ldots \ldots .\end{cases} \\
C_{n}= \begin{cases}\frac{N !}{(N-n) ! n !}\left(\frac{\lambda}{\mu}\right)^{n} & \text { untuk } \mathrm{n}=0,1,2, \ldots, \mathrm{s} \\
\frac{N !}{(N-n) ! s ! s^{n-s}}\left(\frac{\lambda}{\mu}\right)^{n} \text { untuk } \mathrm{n}=\mathrm{s}, \mathrm{s}+1, \ldots, \mathrm{N} \\
0\end{cases}
\end{gathered}
$$

Keterangan :

$\mathrm{N}=$ jumlah populasi dalam satu wilayah perumahan

$\mathrm{n}=$ jumlah objek dalam sistem antrian

$\lambda=$ kecepatan kedatangan pelanggan

$\mu=$ kecepatan pelayanan

$\mathrm{s}=$ jumlah server

$\mathrm{C}_{\mathrm{n}}=$ faktor antrian

Berikut ini adalah persamaan-persamaan untuk menganalisis kinerja antrian multiple server dengan populasi terbatas yang diturunkan dari model matematis (Kalyanaraman \& Mahalakshmi, 2014):

a. Probabilitas n objek dalam antrian $\left(\mathrm{P}_{\mathrm{n}}\right)$

$$
P_{n}=\left\{\begin{array}{l}
\frac{N !}{(N-n) ! n !}\left(\frac{\lambda}{\mu}\right)^{n} P_{0} \text { jika } 0 \leq \mathrm{n} \leq \mathrm{s} \\
\frac{\mathrm{N} !}{(\mathrm{N}-\mathrm{n}) ! s ! s^{n-s}}\left(\frac{\lambda}{\mu}\right)^{n} P_{0} \text { jika } \mathrm{s} \leq \mathrm{n} \leq \mathrm{N} \\
0 \quad \text { Jika } \mathrm{n}>\mathrm{N}
\end{array}\right.
$$


b. Probabilitas tidak ada objek dalam antrian $\left(\mathrm{P}_{0}\right)$

$$
P_{0}=\frac{1}{\left[\sum_{n=0}^{s-1} \frac{N !}{(N-n) ! n !}\left(\frac{\lambda}{\mu}\right)^{n}+\sum_{n=s}^{N} \frac{N !}{(N-n) ! n ! s^{n-s}}\left(\frac{\lambda}{\mu}\right)^{n}\right]}
$$

c. Jumlah objek dalam antrian $\left(\mathrm{L}_{\mathrm{q}}\right)$

$$
L_{q}=\sum_{n=s}^{N}(n-s) P_{n}
$$

d. Jumlah objek dalam sistem (L)

$$
L=\sum_{n=0}^{s-1} n P_{n}+L_{q}+s\left(1-\sum_{n=0}^{s-1} P_{n}\right)
$$

2.5 Optimasi jumlah truk pengangkut sampah

Biaya server atau biaya tenaga kerja dan biaya antrian harus dihitung untuk menentukan jumlah truk pengangkut sampah yang optimal.

1. Penentuan biaya server atau biaya tenaga kerja truk pengangkut sampah yang terdiri atas biaya tenaga kerja dan biaya bahan bakar.

2. Penentuan biaya antrian

Biaya antrian berkenaan dengan biaya yang diakibatkan oleh penumpukan sampah di depan setiap rumah warga.

a. Biaya penyediaan tempat penampungan sampah.

b. Biaya yang diakibatkan oleh risiko terpapar penyakit.

c. Biaya area tempat penampungan sampah liar

d. Biaya pengangkutan sampah yang berasal dari tempat penampungan sampah liar.

\section{Hasil dan Pembahasan}

Pengumpulan data dilakukan pada perumahan di daerah tembesi Kota Batam yang terbagi menjadi 4 wilayah. Analisis dilakukan pada setiap wilayah.

\subsection{Kecukupan Jumlah Data Penelitian}

Jumlah data kecepatan kedatangan pelanggan dan kecepatan pelayanan masing-masing sebesar 180 . Uji kecukupan data dihitung dengan menggunakan persamaan (3). Persamaan tersebut diturunkan dengan nilai probabilitas pada nilai kristis distribusi hipotesis nol sebesar 0,5 dan nilai probabilitas pada nilai kritis hipotesis alternatif sebesar 0,2. $\theta_{0}$ merupakan hipotesis nol dan $\theta_{1}$ merupakan hipotesis alternatif.

1. Perhitungan kecukupan jumlah data kecepatan kedatangan pelanggan

Perhitungan dilakukan persamaan rules of thumb dengan persamaan (3). Hipotesis nol sama dengan 4 dan hipotesis alternatif sama dengan 5 sehingga

$n_{\text {kecepatankedat anganpelanggan }}=\frac{4}{(\sqrt{11}-\sqrt{10})^{2}}=167,90$

. Jumlah data sebesar 180 melebihi jumlah sampel minimum 167,90 sehingga jumlah data cukup.
2. Perhitungan kecukupan jumlah data untuk data kecepatan pelayanan

Perhitungan dilakukan dengan menggunakan pendekatan rules of thumb dengan persamaan (3). Hipotesis nol sama dengan 12 dan hipotesis alternatif sama dengan 10,5 sehingga jumlah data minimum adalah sebesar :

$$
n_{\text {kecepatankedatanganpelanggan }}=\frac{4}{(\sqrt{12}-\sqrt{10,5})^{2}}=79,91
$$

Jumlah data sebesar 180 melebihi jumlah sampel minimum 79,91 sehingga jumlah data cukup.

\subsection{Uji Distribusi Data}

Uji distribusi data dilakukan pada data kecepatan kedatangan pelanggan (yang dalam hal ini adalah pertambahan jumlah rumah yang tempat sampahnya terisi dan pertambahan tersebut dihitung per jam). Agar data tersebut dapat digunakan untuk simulasi dan dapat digunakan untuk perhitungan, data tersebut harus berdistribusi poison. Uji distribusi data dilakukan dengan bantuan program minitab sebagai berikut.

1. Uji distribusi data kecepatan kedatangan Nilai $\chi^{2}$ hitung adalah sebesar 1,78837. Nilai $\chi^{2}$ tabel yang ditentukan pada tingkat keyakinan 5 persen dan derajat bebas 8 sebesar 15,50731306 (CHISQ.INV $(0,05 ; 8))$. Nilai $\chi^{2}$ hitung lebih kecil dari tabel sehingga data kecepatan kedatangan berdistribusi poison. Uji distribusi kecepatan kedatangan juga dilakukan pada wilayah II, wilayah III dan wilayah IV dan hasil uji $\chi^{2}$ disajikan pada

Tabel 1.

Tabel 1. Uji Distribusi Kecepatan Kedatangan Pelanggan

\begin{tabular}{ccccc}
\hline Wil. & DF & $\chi^{2}$ Hitung & $\chi^{2}$ Tabel & Distribusi \\
\hline II & 10 & 7,35 & 18,31 & Poison \\
\hline III & 8 & 5,09 & 15,51 & Poison \\
\hline IV & 10 & 9,82 & 18,31 & Poison \\
\hline
\end{tabular}

2. Uji Distribusi Data Kecepatan Pelayanan Nilai chisquare hitung adalah sebesar 10,3914. Nilai $\chi^{2}$ tabel yang ditentukan pada tingkat keyakinan 5 persen dan derajat bebas 14 sebesar 23,6847913 (CHISQ.INV(0,05; 14)). Nilai $\chi^{2}$ hitung lebih kecil dari tabel sehingga data kecepatan pelayanan berdistribusi poison. Uji distribusi kecepatan pelayanan juga dilakukan pada wilayah II, wilayah III dan wilayah IV dan hasil uji $\chi^{2}$ disajikan pada Tabel 2. 
Tabel 2. Uji Distribusi Kecepatan Pelayanan

\begin{tabular}{ccccc}
\hline Wilayah & DF & $\begin{array}{c}\chi^{2} \\
\text { Hitung }\end{array}$ & $\chi^{2}$ Tabel & Distribusi \\
\hline II & 13 & 6,17 & 22,36 & Poison \\
\hline III & 14 & 8,34 & 23,68 & Poison \\
\hline IV & 14 & 9,16 & 23,68 & Poison \\
\hline
\end{tabular}

3.3 Analisis Karakteristik Antrian dengan Jumlah Truk $=1$

1. Rata-rata kecepatan kedatangan pelanggan dan kecepatan pelayanan pada setiap wilayah dihitung dengan persamaan (7) dan hasil perhitungan disajikan pada Tabel 3 dan 4.

Tabel 3. Nilai Rata-Rata Kecepatan Kedatangan Pelanggan

\begin{tabular}{cc}
\hline Wilayah & $\begin{array}{c}\text { Rata-rata kecepatan kedatangan } \\
\text { pelanggan per hari }\end{array}$ \\
\hline I & 4,32 \\
\hline II & 5,71 \\
\hline III & 4,67 \\
\hline IV & 6,52 \\
\hline
\end{tabular}

Tabel 4. Nilai Rata-Rata Kecepatan Pelayanan Pelanggan

\begin{tabular}{cc}
\hline Wilayah & $\begin{array}{c}\text { Rata-rata kecepatan pelayanan per } \\
\text { jam }\end{array}$ \\
\hline I & 11,13 \\
\hline II & 10,14 \\
\hline III & 9,89 \\
\hline IV & 11,59 \\
\hline
\end{tabular}

2. Menghitung nilai $\mathrm{P}_{0 \text {. }}$

Jumlah rumah yang berpenghuni pada wilayah I adalah sebesar 160. Rata-rata kecepatan kedatangan pelanggan pada wilayah I adalah sebesar 4,3167 $\frac{\text { Pelanggan }}{\text { hari }}$. Rata-rata kecepatan pelayanan pelanggan pada wilayah I adalah sebesar 11,33 $\frac{\text { Pelanggan }}{\text { Jam }}=267,2 \frac{\text { Pelanggan }}{\text { hari }}, \quad$ Sehingga $\lambda=4,3167 \frac{\text { Pelanggan }}{\text { hari }}$ dan $\mu=267,2 \frac{\text { Pelanggan }}{\text { hari }}$.

Nilai $\mathrm{P}_{0}$ dihitung sebagai berikut:

$$
\begin{aligned}
\mathrm{P}_{0}=\frac{1}{\sum_{\mathrm{n}=0}^{\mathrm{N}} \frac{\mathrm{N} !}{(\mathrm{N}-\mathrm{n}) !}\left(\frac{\lambda}{\mu}\right)^{\mathrm{n}}} & =\frac{1}{\sum_{\mathrm{n}=0}^{160} \frac{160 !}{(\mathrm{N}-\mathrm{n}) !}\left(\frac{4,3167}{267,2}\right)^{\mathrm{n}}} \\
& =1,3 \times 10^{-25}
\end{aligned}
$$

3. Menghitung nilai Pn.

Probabilitas adanya 1 pelanggan dalam sistem jika jumlah truk hanya 1 buah dihitung sebagai berikut : $P_{1}=\frac{160 !}{(160-1) !}\left(\frac{4,3167}{267,2}\right)^{n}=3,36 \times 10^{-25}$.

4. Menghitung nilai Lq (jumlah pelanggan dalam antrian).
$L_{q}=\sum_{\mathrm{n}=1}^{160}(\mathrm{n}-1) \mathrm{P}_{\mathrm{n}}=97,100386$.

5. Menghitung nilai L (jumlah pelanggan dalam sistem).

$\mathrm{L}=\mathrm{N}-\frac{\mu}{\lambda}\left(1-\mathrm{P}_{0}\right)=160-\frac{267,2}{4,3167}\left(1-\left(1,3 \times 10^{-25}\right)\right)=98,1$

6. Menghitung nilai $\bar{\lambda}$.

$\bar{\lambda}=\lambda(\mathrm{N}-\mathrm{L})=4,3167(160-98,100386)=267,2 \frac{\text { Pelanggan }}{\text { hari }}$

7. Menghitung waktu yang diperlukan pelanggan untuk berada dalam sistem (Wq).

$\mathrm{W}_{\mathrm{q}}=\frac{\mathrm{L}_{\mathrm{q}}}{\bar{\lambda}}=\frac{97,100386 \text { pelanggan }}{267,2 \frac{\text { pelanggan }}{\text { hari }}} \times 24 \frac{\mathrm{jam}}{\text { hari }}=8,7215916 \mathrm{jam}$

8. Menghitung waktu yang diperlukan pelanggan untuk berada dalam sistem antrian $(\mathrm{W})$.

$$
\mathrm{W}=\frac{\mathrm{L}}{\bar{\lambda}}=\frac{98,100386 \text { pelanggan }}{267,2 \frac{\text { pelanggan }}{\text { hari }}} \times 24 \frac{\text { jam }}{\text { hari }}=8,8114119 \text { jam }
$$

9. Langkah 1 sampai 9 dilakukan untuk menghitung $\mathrm{P}_{0}, \mathrm{Pn}, \mathrm{Lq}, \mathrm{L}, \bar{\lambda}, \mathrm{Wq}$ dan $\mathrm{W}$ pada wilayah II, III dan IV dan hasilnya disajikan pada Tabel 5.

Tabel 5. Karakteristik Antrian pada Tiap Wilayah dengan Jumlah Truk Sebesar 1

\begin{tabular}{cccccccc}
\hline Wil. & $\mathbf{P}_{\mathbf{0}}$ & $\begin{array}{c}\mathbf{P n} \\
(\mathbf{1})\end{array}$ & $\mathbf{L q}$ & $\mathbf{L}$ & $\bar{\lambda}$ & $\mathbf{W}_{\mathbf{q}}$ & $\mathbf{W}$ \\
\hline \multirow{2}{*}{$\mathrm{I}$} & $\begin{array}{c}1 \mathrm{E}- \\
25\end{array}$ & $\begin{array}{c}3 \mathrm{E}- \\
25\end{array}$ & $\begin{array}{c}97,1 \\
0\end{array}$ & 98,1 & $\begin{array}{c}267, \\
2\end{array}$ & 8,7 & 8,8 \\
\hline \multirow{2}{*}{ II } & $\begin{array}{c}3 \mathrm{E}- \\
39\end{array}$ & $\begin{array}{c}1 \mathrm{E}- \\
38\end{array}$ & $\begin{array}{c}109, \\
4\end{array}$ & $\begin{array}{c}110, \\
4\end{array}$ & $\begin{array}{c}243, \\
3\end{array}$ & 10,8 & 10,9 \\
\hline \multirow{2}{*}{$\mathrm{III}$} & $\begin{array}{c}5 \mathrm{E}- \\
36\end{array}$ & $\begin{array}{c}2 \mathrm{E}- \\
35\end{array}$ & $\begin{array}{c}111, \\
2\end{array}$ & $\begin{array}{c}112, \\
2\end{array}$ & $\begin{array}{c}237, \\
3\end{array}$ & 11,2 & 11,3 \\
\hline \multirow{2}{*}{ IV } & $2 \mathrm{E}-$ & $\begin{array}{c}7 \mathrm{E}- \\
35\end{array}$ & $\begin{array}{c}102, \\
4\end{array}$ & $\begin{array}{c}103, \\
4\end{array}$ & $\begin{array}{c}278, \\
1\end{array}$ & 8,8 & 8,9 \\
\hline
\end{tabular}

3.4 Analisis Karakteristik Antrian dengan Jumlah Truk Lebih Besar dari 1

Analisis berikut ini dilakukan pada wilayah I.

1. Rata-rata kecepatan kedatangan pelanggan dan kecepatan pelayanan.

Rata-rata kecepatan kedatangan pelanggan dan pelayanan dihitung dengan persamaan (7) dan hasilnya disajikan pada Tabel 3 dan Tabel 4.

2. Perhitungan nilai $\mathrm{P}_{0}$.

Jumlah rumah yang berpenghuni pada wilayah I adalah sebesar 160. Rata-rata kecepatan kedatangan pelanggan pada wilayah I adalah sebesar 4,3167

$\frac{\text { Pelanggan }}{\text { hari }}$. Rata-rata kecepatan pelayanan pelanggan pada wilayah I adalah sebesar 11,33 $\frac{\text { Pelanggan }}{\text { Jam }}=267,2 \frac{\text { Pelanggan }}{\text { hari }}, \quad$ Sehingga 


$$
\begin{gathered}
\lambda=4,3167 \frac{\text { Pelanggan }}{\text { hari }} \\
\mu=267,2 \frac{\text { Pelanggan }}{\text { hari }} \\
\mathrm{P}_{0}=\frac{1}{\sum_{\mathrm{n}=0}^{\mathrm{N}} \mathrm{C}_{\mathrm{n}}}=\frac{\sum_{\mathrm{n}=0}^{\mathrm{s}-1} \frac{\mathrm{N} !}{(\mathrm{N}-\mathrm{n}) ! \mathrm{n} !}\left(\frac{\lambda}{\mu}\right)^{\mathrm{n}}+\sum_{\mathrm{n}=\mathrm{s}}^{\mathrm{N}} \frac{\mathrm{N} !}{(\mathrm{N}-\mathrm{n}) ! \mathrm{s} ! \mathrm{s}^{\mathrm{n}-\mathrm{s}}\left(\frac{\lambda}{\mu}\right)^{\mathrm{n}}}}{\mathrm{P}_{0}=} \frac{1 \text { dan }}{\sum_{\mathrm{n}=0}^{2-1} \frac{160 !}{(160-\mathrm{n}) ! \mathrm{n} !}\left(\frac{4,3167}{267,2}\right)^{\mathrm{n}}+\sum_{\mathrm{n}=2}^{160} \frac{160 !}{(160-\mathrm{n}) ! 2 ! 2^{\mathrm{n}-2}}\left(\frac{4,3167}{267,2}\right)^{\mathrm{n}}}=0,000125
\end{gathered}
$$

3. Perhitungan nilai $P_{n}$

$$
P_{n}= \begin{cases}\frac{160 !}{(160-n) ! n !}\left(\frac{4,3167}{267,2}\right)^{n}(0,000125) & \text { Jika } 0 \leq n \leq 2 \\ \frac{160 !}{(160-n) ! 2 ! 2^{n-2}}\left(\frac{4,3167}{267,2}\right)^{n}(0,000125) & \text { Jika } \mathrm{s} \leq \mathrm{n} \leq \mathrm{N} \\ 0 \quad \text { Jika } \mathrm{n}>\mathrm{N} & \end{cases}
$$

4. Menghitung nilai $\mathrm{Lq}$ (jumlah pelanggan dalam antrian).

$$
\sum_{n=2}^{160}(n-2) P_{n}=34,2367
$$

5. Menghitung nilai L (jumlah pelanggan dalam sistem).

$$
\begin{aligned}
\mathrm{L} & =\sum_{\mathrm{n}=0}^{2-1} \mathrm{nP}_{\mathrm{n}}+34,240965+2\left(1-\sum_{\mathrm{n}=0}^{2-1} \mathrm{P}_{\mathrm{n}}\right) \\
& =(2 \times 0,0003221)+34,240965+2(1-(0,000125+0,0003221)) \\
& =36,2361
\end{aligned}
$$

6. Menghitung nilai $\bar{\lambda}$.

$\bar{\lambda}=\lambda(\mathrm{N}-\mathrm{L})=4,3167(160-34,240965)=534,2474 \frac{\text { Pelanggan }}{\text { hari }}$

7. Menghitung waktu yang diperlukan pelanggan untuk berada dalam sistem (W).

\begin{tabular}{|c|c|c|c|c|c|c|c|c|c|c|c|c|}
\hline \multirow{2}{*}{$\begin{array}{l}\text { Kinerja } \\
\text { Antrian }\end{array}$} & \multicolumn{12}{|c|}{ Jumlah Truk (Wilayah I) } \\
\hline & 1 & 2 & 3 & 4 & 5 & 6 & 7 & 8 & 9 & 10 & 11 & 12 \\
\hline $\mathrm{Lq}$ & 97,1 & 34,24 & 2,884 & 0,53 & 0,132 & 0,034 & 0,009 & 0,002 & $\begin{array}{c}4 \mathrm{E}- \\
04\end{array}$ & $\begin{array}{c}9 \mathrm{E}- \\
05\end{array}$ & $\begin{array}{c}2 \mathrm{E}- \\
05\end{array}$ & $\begin{array}{c}3 \mathrm{E}- \\
06\end{array}$ \\
\hline $\mathrm{L}$ & 98,1 & 36,24 & 5,381 & 3,065 & 2,674 & 2,577 & 2,552 & 2,546 & 2,544 & 2,544 & 2,544 & 2,544 \\
\hline $\bar{\lambda}$ & 267,2 & 534,2 & 667,4 & 677,4 & 679,1 & 679,5 & 679,6 & 679,7 & 679,7 & 679,7 & 679,7 & 679,7 \\
\hline $\mathrm{W}(\mathrm{jam})$ & 8,811 & 1,628 & 0,194 & 0,109 & 0,094 & 0,091 & 0,09 & 0,09 & 0,09 & 0,09 & 0,09 & 0,09 \\
\hline Wq (jam) & 8,722 & 1,538 & 0,104 & 0,019 & 0,005 & 0,001 & $\begin{array}{c}3 \mathrm{E}- \\
04\end{array}$ & $\begin{array}{c}7 \mathrm{E}- \\
05\end{array}$ & $\begin{array}{c}2 \mathrm{E}- \\
05\end{array}$ & $\begin{array}{c}3 \mathrm{E}- \\
06\end{array}$ & $\begin{array}{c}\text { 6E- } \\
07\end{array}$ & $\begin{array}{c}\text { 1E- } \\
07\end{array}$ \\
\hline
\end{tabular}

$\mathrm{W}=\frac{\mathrm{L}}{\bar{\lambda}}=\frac{34,240965 \text { pelanggan }}{534,22897 \frac{\text { pelanggan }}{\text { hari }}} \times 24 \frac{\text { jam }}{\text { hari }}=1,6278$ jam

8. Menghitung waktu yang diperlukan pelanggan

\begin{tabular}{|c|c|c|c|c|c|c|c|c|c|c|c|c|}
\hline \multirow{2}{*}{$\begin{array}{l}\text { Kinerja } \\
\text { Antrian }\end{array}$} & \multicolumn{12}{|c|}{ Jumlah Truk (Wilayah II) } \\
\hline & 1 & 2 & 3 & 4 & 5 & 6 & 7 & 8 & 9 & 10 & 11 & 12 \\
\hline $\mathrm{Lq}$ & 109,4 & 65,79 & 22,69 & 3,305 & 0,771 & 0,225 & 0,069 & 0,021 & 0,006 & 0,002 & $\begin{array}{c}4 \mathrm{E}- \\
04\end{array}$ & $\begin{array}{l}9 \mathrm{E}- \\
05\end{array}$ \\
\hline $\mathrm{L}$ & 110,4 & 67,79 & 25,68 & 6,738 & 4,262 & 3,729 & 3,576 & 3,529 & 3,514 & 3,51 & 3,509 & 3,509 \\
\hline $\bar{\lambda}$ & 243,3 & 486,7 & 727,1 & 835,3 & 849,5 & 852,5 & 853,4 & 853,6 & 853,7 & 853,8 & 853,8 & 853,8 \\
\hline $\mathrm{W}$ (jam) & 10,89 & 3,343 & 0,848 & 0,194 & 0,12 & 0,105 & 0,101 & 0,099 & 0,099 & 0,099 & 0,099 & 0,099 \\
\hline $\mathrm{Wq}(\mathrm{jam})$ & 10,79 & 3,244 & 0,749 & 0,095 & 0,022 & 0,006 & 0,002 & $\begin{array}{c}6 \mathrm{E}- \\
04\end{array}$ & $\begin{array}{c}2 \mathrm{E}- \\
04\end{array}$ & $\begin{array}{c}4 \mathrm{E}- \\
05\end{array}$ & $\begin{array}{c}1 \mathrm{E}- \\
05\end{array}$ & $\begin{array}{c}3 \mathrm{E}- \\
06\end{array}$ \\
\hline
\end{tabular}
untuk berada dalam antrian $\left(\mathrm{W}_{\mathrm{q}}\right)$.

$$
\mathrm{W}_{\mathrm{q}}=\frac{\mathrm{L}_{\mathrm{q}}}{\bar{\lambda}}=\frac{36,24 \text { pelanggan }}{534,22897 \frac{\text { pelanggan }}{\text { hari }}} \times 24 \frac{\mathrm{jam}}{\text { hari }}=1,5380 \mathrm{jam}
$$

Langkah 1 sampai 9 dilakukan pada wilayah II, III dan IV. Hasil perhitungan disajikan pada Tabel 6 sampai 9.

Tabel 6. Perhitungan Kinerja Antrian dengan 2 Truk pada Wilayah I

Tabel 7. Perhitungan Kinerja Antrian dengan Truk $>1$ pada Wilayah II 
Tabel 8. Perhitungan Kinerja Antrian dengan Truk $>1$ pada Wilayah III

\begin{tabular}{|c|c|c|c|c|c|c|c|c|c|c|c|c|}
\hline \multirow{2}{*}{$\begin{array}{l}\text { Kinerja } \\
\text { Antrian }\end{array}$} & \multicolumn{12}{|c|}{ Jumlah Truk (Wilayah III) } \\
\hline & 1 & 2 & 3 & 4 & 5 & 6 & 7 & 8 & 9 & 10 & 11 & 12 \\
\hline $\mathrm{Lq}$ & 111,2 & 59,41 & 12,21 & 1,7 & 0,419 & 0,12 & 0,034 & 0,01 & 0,003 & $\begin{array}{c}6 \mathrm{E}- \\
04\end{array}$ & $\begin{array}{c}1 \mathrm{E}- \\
04\end{array}$ & $\begin{array}{c}3 \mathrm{E}- \\
05\end{array}$ \\
\hline $\mathrm{L}$ & 112,2 & 61,41 & 15,12 & 4,814 & 3,558 & 3,264 & 3,181 & 3,156 & 3,149 & 3,148 & 3,147 & 3,147 \\
\hline $\bar{\lambda}$ & 237,3 & 474,7 & 690,9 & 739,1 & 745 & 746,3 & 746,7 & 746,8 & 746,9 & 746,9 & 746,9 & 746,9 \\
\hline $\mathrm{W}($ jam $)$ & 11,35 & 3,105 & 0,525 & 0,156 & 0,115 & 0,105 & 0,102 & 0,101 & 0,101 & 0,101 & 0,101 & 0,101 \\
\hline $\mathrm{Wq}$ (jam) & 11,25 & 3,004 & 0,424 & 0,055 & 0,013 & 0,004 & 0,001 & $\begin{array}{c}3 \mathrm{E}- \\
04\end{array}$ & $\begin{array}{c}8 \mathrm{E}- \\
05\end{array}$ & $\begin{array}{c}2 \mathrm{E}- \\
05\end{array}$ & $\begin{array}{c}\text { 4E- } \\
06\end{array}$ & $\begin{array}{c}1 \mathrm{E}- \\
06\end{array}$ \\
\hline
\end{tabular}

Tabel 9. Perhitungan kinerja antrian dengan dengan truk $>1$ pada wilayah IV

\begin{tabular}{ccccccccccccc}
\hline Kinerja & \multicolumn{110}{c}{ Jumlah Truk (Wilayah IV) } \\
\cline { 2 - 13 } & $\mathbf{1}$ & $\mathbf{2}$ & $\mathbf{3}$ & $\mathbf{4}$ & $\mathbf{5}$ & $\mathbf{6}$ & $\mathbf{7}$ & $\mathbf{8}$ & $\mathbf{9}$ & $\mathbf{1 0}$ & $\mathbf{1 1}$ & $\mathbf{1 2}$ \\
\hline Lq & 102,4 & 58,78 & 16,73 & 2,419 & 0,585 & 0,17 & 0,051 & 0,015 & 0,004 & 0,001 & $\begin{array}{c}2 \mathrm{E}- \\
04\end{array}$ & $\begin{array}{c}6 \mathrm{E}- \\
05\end{array}$ \\
\hline $\mathrm{L}$ & 103,4 & 60,78 & 19,7 & 5,712 & 3,92 & 3,514 & 3,398 & 3,362 & 3,352 & 3,349 & 3,348 & 3,348 \\
\hline $\bar{\lambda}$ & 278,1 & 556,3 & 824,5 & 915,8 & 927,5 & 930,1 & 930,9 & 931,1 & 931,2 & 931,2 & 931,2 & 931,2 \\
\hline W (jam) & 8,922 & 2,623 & 0,573 & 0,15 & 0,101 & 0,091 & 0,088 & 0,087 & 0,086 & 0,086 & 0,086 & 0,086 \\
\hline Wq (jam) & 8,835 & 2,536 & 0,487 & 0,063 & 0,015 & 0,004 & 0,001 & $\begin{array}{c}4 \mathrm{E}- \\
04\end{array}$ & $\begin{array}{c}1 \mathrm{E}- \\
04\end{array}$ & $\begin{array}{c}3 \mathrm{E}- \\
05\end{array}$ & $\begin{array}{c}6 \mathrm{E}- \\
06\end{array}$ & $\begin{array}{c}1 \mathrm{E}- \\
06\end{array}$ \\
\hline
\end{tabular}

\subsection{Optimasi Biaya Antrian}

1. Penentuan biaya server atau biaya tenaga kerja truk pengangkut sampah yang terdiri atas biaya tenaga kerja dan biaya bahan bakar.

a. Biaya tenaga kerja

Terdapat 5 orang yang bekerja pada satu truk sampah. Biaya tenaga kerja sebesar 3 juta per orang per bulan. Jumlah hari kerja per bulan adalah 20 hari kerja, sehingga biaya tenaga kerja per hari adalah $\frac{\mathrm{Rp} .3 \mathrm{juta}}{20}=\mathrm{Rp} 150.000,-$. Total biaya lima orang tenaga kerja per hari adalah sebesar Rp 750.000,-.

b. Biaya bahan bakar

Truk pengangkut sampah yang beroperasi memiliki mesin dengan kapasitas 4000 cc dan dengan rata-rata konsumsi bahan bakar solar sebesar $3,5 \mathrm{~km}$ per liter. Total panjang rute dihitung dengan cara mengukur panjang lintasan truk sampah di sepanjang perumahan. Total biaya truk per wilayah disajikan pada Tabel 10.

Tabel 10. Total Biaya Truk per Wilayah

\begin{tabular}{cccc}
\hline Wilayah & $\begin{array}{c}\text { Biaya } \\
\text { Bahan } \\
\text { Bakar (Rp) }\end{array}$ & $\begin{array}{c}\text { Biaya } \\
\text { Tenaga } \\
\text { Kerja (Rp) }\end{array}$ & $\begin{array}{c}\text { Biaya Truk per } \\
\text { Hari (Rp) }\end{array}$ \\
\hline I & $82.053,32$ & $750.000,00$ & $832.053,32$ \\
\hline II & $81.508,89$ & $750.000,00$ & $831.508,89$ \\
\hline III & $82.862,60$ & $750.000,00$ & $832.862,60$ \\
\hline IV & $80.808,26$ & $750.000,00$ & $830.808,26$ \\
\hline
\end{tabular}

2. Perhitungan biaya antrian
Biaya antrian berkenaan dengan biaya yang diakibatkan oleh penumpukan sampah di depan setiap rumah warga.

a. Biaya penyediaan tempat penampungan sampah.

Setiap warga harus menyediakan tempat untuk menampung sampah yang cukup untuk menampung 5 bungkus besar atau kurang lebih $20 \mathrm{~kg}$ sampah. Tempat yang disediakan memiliki luas rata-rata sebesar $2 \mathrm{~m}^{2}$. Biaya sewa perbulan rumah tipe 36/ 72 di perumahan tersebut adalah Rp 1.000.000,-. Biaya sewa adalah $\frac{\text { Rp. } 1 \cdot 000.000}{72 \mathrm{~m}^{2} \text {.bulan }} \times 2 \mathrm{~m}^{2} \times \frac{1 \text { bulan }}{30 \text { hari }}=\mathrm{Rp} 925,93 /$ hari .

Sehingga warga harus menyediakan tempat penampungan sampah dengan biaya sewa sebesar Rp 925,93 per hari.

b. Biaya kesehatan yang diakibatkan oleh penyakit dari sampah yang menumpuk di depan rumah warga

Sampah yang menumpuk di depan rumah warga dapat menimbulkan penyakit. Data yang diambil dari puskesmas setempat menyatakan terdapat warga yang mengalami diare, muntaber, dan tifus harus dirawat inap di rumah sakit. Berdasarkan data tersebut, terdapat biaya kesehatan yang harus disediakan. Besar biaya kesehatan tersebut diasumsikan sama dengan biaya rawat inap rumah sakit kelas 3 sebesar Rp 39.000,per hari.

c. Biaya area tempat penampungan sampah liar

Warga yang masuk dalam antrian merupakan warga yang jumlah sampahnya melebihi 5 bungkus besar atau melebihi $20 \mathrm{~kg}$. Jika sampah tersebut tidak diangkut maka warga akan cenderung membuang sampahnya di tempat 
penampungan sampah liar yang ada di depan TPS liar. Area tempat penampungan sampah liar yang ada di depan lapangan perumahan memiliki luas area $5 \mathrm{~m} \times 10 \mathrm{~m}=50 \mathrm{~m}^{2}$. Total jumlah sampah yang ada di area tersebut adalah sekitar 1 kontainer truk sampah atau 5 ton sampah yang setara dengan $\begin{array}{lll}\text { sampah dari } & 250 \quad \text { rumah }\end{array}$ $\left\{\frac{5000 \mathrm{~kg}}{20 \mathrm{~kg} / 1 \text { rumah }}=250 \mathrm{rumah}\right\}$. Total biaya penyediaan tempat penampungan sampah liar per hari adalah

$\frac{\text { Rp. } 1.000 .000}{72 \mathrm{~m}^{2}} \times 50 \mathrm{~m}^{2} \times \frac{1 \text { bulan }}{30 \text { hari }}=\mathrm{Rp} 23.148,15 /$ hari

Biaya area tempat pembuangan sampah liar per rumah adalah $\frac{\operatorname{Rp} 23.148,15-}{250}=R$ R2,59/hari

d. Biaya pengangkutan sampah yang berasal dari tempat penampungan sampah liar.

Untuk mengangkut sampah yang ada di tempat pembuangan sampah liar diperlukan tambahan 1 mobil truk dengan 5 orang tenaga kerja. Total jumlah sampah yang ada di tempat pembuangan sampah liar adalah 1 kontainer penuh atau sekitar 5 ton atau setara dengan sampah dari 250 rumah. Perhitungan biaya pengangkutan sampah liar meliputi biaya bahan bakar dan biaya tenaga kerja.

1) Biaya bahan bakar

Rata-rata jarak tempat pembuangan sampah liar ke tempat pembuangan akhir di kabil adalah 25,28
Km. Rata-rata biaya bahan bakar adalah $2 \times 25,28 \mathrm{~km} \times \frac{1 \text { liter }}{3,5 \mathrm{~km}} \times \frac{\mathrm{Rp} 5.150}{\text { liter }}=\mathrm{Rp} 74.401,31$

Rata-rata biaya bahan bakar per rumah adalah $\frac{\mathrm{Rp} 74.401,31}{250 \text { rumah }}=\mathrm{Rp297,61,-} /$ rumah

2) Biaya tenaga kerja.

Biaya tenaga kerja pengangkutan sampah dari tempat pembuangan sampah liar adalah sebesar $\left(\frac{5 \text { orang } \times \mathrm{Rp} 150.000 / \text { orang.hari }}{250 \text { rumah }}\right)=\frac{\mathrm{Rp} 3.000}{\text { rumah.hari }}$.

Sehingga total biaya pengangkutan sampah liar adalah Rp297,61 + Rp3.000,- = Rp3.297,61. Total biaya antrian per hari $=\operatorname{Rp} 925.93+\mathrm{Rp} 39.000+$ Rp92,59 + Rp3.297,61 = Rp 43.316,13.

3. Optimasi jumlah truk

Optimasi jumlah truk pengangkut sampah dilakukan melalui perhitungan biaya total yang terdiri dari biaya server atau biaya operasional truk dan biaya antrian. Contoh perhitungan adalah total biaya 3 truk pada wilayah I.

Total biaya wil. $\mathrm{I}=($ Jumlah Antrian $\mathrm{x}$ Biaya Antrian) + (Jumlah Truk x Biaya Truk Wil. I).

Total biaya wil. $\mathrm{I}=(2,884 \mathrm{x} \operatorname{Rp} 43.316,13)+(3 \mathrm{x}$ $832.053,32)=$ Rp. $2.621 .063,16$

Hasil perhitungan total biaya (dalam juta) serta penentuan biaya optimum disajikan pada Tabel 11.

Tabel 11. Optimasi Biaya Antrian

\begin{tabular}{|c|c|c|c|}
\hline \multicolumn{4}{|c|}{ Wilayah I } \\
\hline Jumlah truk & 2 & 3 & 4 \\
\hline $\mathrm{Lq}$ & 34,24 & 2,88 & 0,53 \\
\hline Biaya truk (Rp) & $1.664 .106,63$ & $2.496 .159,95$ & $3.328 .213,27$ \\
\hline Biaya antrian (Rp) & $1.483 .001,32$ & $124.903,21$ & $22.949,79$ \\
\hline Total biaya $(\mathrm{Rp})$ & $3.147 .107,95$ & $2.621 .063,16$ & $3.351 .163,06$ \\
\hline \multicolumn{4}{|c|}{ Wilayah II } \\
\hline Jumlah truk & 2 & 3 & 4 \\
\hline $\mathrm{Lq}$ & 65,79 & 22,69 & 3,30 \\
\hline Biaya truk (Rp) & $1.663 .017,78$ & $2.494 .526,67$ & $3.326 .035,55$ \\
\hline Biaya antrian (Rp) & $2.849 .594,59$ & $982.890,83$ & $143.148,86$ \\
\hline Total biaya (Rp) & $4.512 .612,37$ & $3.477 .417,49$ & $3.469 .184,42$ \\
\hline \multicolumn{4}{|c|}{ Wilayah III } \\
\hline Jumlah truk & 2 & 3 & 4 \\
\hline $\mathrm{Lq}$ & 59,41 & 12,21 & 1,70 \\
\hline Biaya truk (Rp) & $1.665 .725,21$ & $2.498 .587,81$ & $3.331 .450,41$ \\
\hline Biaya antrian (Rp) & $2.573 .266,58$ & $528.801,26$ & $73.631,87$ \\
\hline Total biaya (Rp) & 4.238.991,79 & $3.027 .389,07$ & $3.405 .082,28$ \\
\hline \multicolumn{4}{|c|}{ Wilayah IV } \\
\hline Jumlah truk & 2 & 3 & 4 \\
\hline $\mathrm{Lq}$ & 58,78 & 16,73 & 2,42 \\
\hline Biaya truk (Rp) & $1.661 .616,52$ & $2.492 .424,79$ & $3.323 .233,05$ \\
\hline Biaya antrian (Rp) & $2.546 .324,88$ & $724.814,37$ & $104.790,92$ \\
\hline Total biaya (Rp) & 4.207.941,41 & $3.217 .239,16$ & $3.428 .023,96$ \\
\hline
\end{tabular}


Tabel 11 menunjukkan bahwa jumlah truk sampah yang optimal pada wilayah I, II, III dan IV berturutturut adalah $3,4,3$ dan 3 .

3.6 Pembahasan

Hasil perhitungan menunjukkan bahwa jumlah truk yang optimal berkisar antara 3 dan 4. Implikasi dari hasil perhitungan ini adalah penyediaan truk pengangkut sampah dengan jumlah 3 sampai 4 truk per wilayah perumahan. Jumlah optimal ini masih terlalu banyak dan tidak sesuai dengan kemampuan dinas kebersihan. Sehingga jumlah tersebut perlu dikurangi dengan cara meningkatkan kecepatan pelayanan. Kecepatan pelayanan pengangkutan sampah masih rendah. Kecepatan pelayanan pengangkutan sampah wilayah I, II, III dan IV berturut-turut adalah 267,2 ; 243,3;237,3 dan 278,13. Rata-rata kecepatan pelayanan adalah 256,48 rumah per hari. Rendahnya kecepatan pelayanan ini disebabkan karena beberapa kendala antara lain yakni:

1. Tempat pembuangan sampah warga sulit dijangkau petugas kebersihan. Beberapa warga menempatkan tempat sampahnya pada paku-paku yang ditancap di pagar sehingga petugas harus mengangkutnya satu persatu. Beberapa warga juga menempatkan tempat sampahnya terhalang dengan wadah tanaman sehingga petugas harus melewati beberapa pot tanaman untuk mengangkut sampah. Selain itu ada beberapa tempat sampah yang terbuat dari anyaman bambu yang telah rusak sehingga sulit diangkat.

2. Handle tempat sampah tidak nyaman untuk dipegang atau diangkat sehingga petugas kebersihan harus melapisinya dengan kain agar tangan petugas tidak terluka.

3. Jalan sempit sehingga menyulitkan truk pengangkut sampah untuk bermanuver. Sampah pada rumah yang jalannya sempit seringkali tidak diambil petugas karena truk pengangkut sampah tidak dapat lewat.

4. Mobil pribadi yang diparkir di pinggir jalan menyulitkan truk sampah untuk melewati dan mengambil sampah di tiap rumah warga.

5. Sampah basah yang ada dalam tempat sampah sulit dikeluarkan karena sampah basah tersebut bocor dan sampah lengket pada tempat sampah sehingga petugas kebersihan harus membanting tempat sampah berkali-kali agar sampah basah keluar.

Beberapa perbaikan perlu dilakukan untuk meningkatkan pelayanan. Usulan perbaikan diimplementasikan kepada warga yang ada di wilayah I.

1. Tempat pembuangan sampah distandarkan bentuknya. Drum plastik digergaji menjadi 2 bagian. Bagian pegangannya dihaluskan dengan amplas agar tidak melukai tangan petugas kebersihan. Bagian atas tempat sampah diberi tutup agar tidak ada hewan yang merusak isi tempat sampah sehingga sampah basah tidak tercerai berai dan tempat sampah mudah dikosongkan. Bagian dasar tempat sampah diberi lubang agar tempat sampah tetap kering dan tidak berbau.

2. Tempat sampah diletakkan di lokasi yang tidak terhalang sehingga petugas kebersihan mudah mengambilnya.

3. Menghimbau warga agar memarkir mobilnya dengan baik agar tidak menganggu lalu lintas.

4. Memisahkan sampah menjadi 2 bagian yakni sampah organik dan anorganik.

Implementasi usulan perbaikan tersebut berdampak pada kenaikan kecepatan pelayanan pengangkutan sampah di perumahan wilayah I dari 267,2 rumah per hari menjadi 480,8 rumah per hari. Jumlah truk yang optimum pada wilayah I setelah implementasi perbaikan adalah 1. Kinerja antrian setelah dilakukan perbaikan disajikan pada Tabel 12. Uji t 2 populasi dependen dilakukan untuk menentukan signifikansi dampak perbaikan pada kinerja antrian. Variabel yang akan diuji tingkat signifikansinya adalah variabel $\mathrm{L}$. L merupakan jumlah pelanggan yang berada di dalam sistem. Nilai $t$ hitung adalah 1.762. Nilai t tabel dengan derajat bebas sebesar 11 dan tingkat kepercayaan sebesar $5 \%$ one tail adalah 1,717. Nilai t hitung lebih besar dari t tabel sehingga rata-rata jumlah pelanggan dalam sistem berkurang secara signifikan setelah dilakukan implementasi perbaikan.

Tabel 12. Kinerja Antrian pada Wilayah I setelah Dilakukan Perbaikan

\begin{tabular}{ccccccc}
\hline \multirow{2}{*}{ Kinerja Antrian } & \multicolumn{7}{c}{ JUMLAH TRUK } \\
\cline { 2 - 7 } & $\mathbf{1}$ & $\mathbf{2}$ & $\mathbf{3}$ & $\mathbf{4}$ & $\mathbf{5}$ & $\mathbf{6}$ \\
\hline Po & $2,78 \mathrm{E}-06$ & 0,1711 & 0,2287 & 0,2376 & 0,239 & 0,2392 \\
\hline $\mathrm{Lq}$ & 47,6181 & 1,2985 & 0,1807 & 0,0332 & 0,0061 & 0,001 \\
\hline $\mathrm{L}$ & 48,6181 & 2,7106 & 1,6028 & 1,4567 & 1,4297 & 1,4247 \\
\hline $\bar{\lambda}$ & 480,799 & 678,97 & 683,75 & 684,38 & 684,5 & 684,52 \\
\hline $\mathrm{W}($ jam) & 2,42687 & 0,0958 & 0,0563 & 0,0511 & 0,0501 & 0,05 \\
\hline Wq (jam) & 2,37695 & 0,0459 & 0,0063 & 0,0012 & 0,0002 & $4 \mathrm{E}-05$ \\
\hline Biaya Antrian (Rp) & $2.062 .630,65$ & $56.245,48$ & $7.827,69$ & $1.439,90$ & 262,72 & 44,51 \\
\hline Biaya Truk (Rp) & $832.053,32$ & $1.664 .106,63$ & $2.496 .159,95$ & $3.328 .213,27$ & $4.160 .266,59$ & $4.992 .319,90$ \\
\hline Total Biaya (Rp) & $2.894 .683,97$ & $1.720 .352,11$ & $2.503 .987,64$ & $3.329 .653,17$ & $4.160 .529,31$ & $4.992 .364,41$ \\
\hline
\end{tabular}

\section{Kesimpulan}


Jumlah truk sampah yang optimum pada kondisi saat ini (current condition) berkisar antara 3 sampai 4 truk. Setelah dilakukan perbaikan, jumlah optimum truk sampah adalah 2 .

\section{Ucapan Terima Kasih}

Kami menyampaikan terima kasih kepada beberapa pihak :

1. Simlitabmas Dikti yang telah memberikan pendanaan penelitian.

2. Universitas Putera Batam yang telah memberikan dukungan dan fasilitas.

\section{Daftar Pustaka}

Aradhye, A., \& Kallurkar, S. (2014). Application of Queuing Theory to Reduce Waiting Period of Pilgrim. International Journal of Innovative Research in Science, Engineering and Technology, 03(10), 16775-16781. https://doi.org/10.15680/IJIRSET.2014.0310052

Belle, G. van. (2008). Statistical Rules of Thumb. (S. Miles, Ed.) (2nd ed.). United States of America: John Wiley \& Sons, Inc.

Benjamin, A. M., Ku-Mahamud, K. R., \& Idrus, Z. (2017). Truck queuing analysis at landfill sites in a waste collection vehicle routing problem. Proceedings of the 6th International Conference on Computing and Informatics, Kuala Lumpur. Universiti Utara Malaysia, (160), 132-138.

Chukwumuanya, E. O., \& Ihueze, C. C. (2017). Mathematical Modeling of Solid Waste Management Processes A Case of Solid Waste Management In Awka City, Anambra. Quest Journals, 3(5), 20-33.

Harison, E., Cherkassky, A., \& Barkai, O. (2016). Improving the organization of waste management sites : Simulation based analysis. Proceedings of the Third European Academic Research Conference on Global Business, Economics, Finance and Banking (EARl6 Paris), 1-8.

Heizer, J., \& Render, B. (2011). Operation Management (Flexible Edition). (S. Yagan, Ed.) (10th ed.). New Jersey: Prentice Hall Boston.

Hillier, F. S., \& Lieberman, G. J. (2015). Introduction to Operation Research. (V. Bradshaw, Ed.) (10th ed.). New York, NY 10121: Mc Graw Hill.

Kalyanaraman, R., \& Mahalakshmi, R. (2014). Finite Population Single Server Batch Service Queue with Compulsory Server Vacation. International Journal of Mathematical Modelling \& Computations, 4(2), 151-165.

Kumar, A. (2013). Existing Situation of Municipal Solid Waste Management in NCT of Delhi, India. International Journal of Social Sciences, 1(1), 617.
Lundin, A. C., Ozkil, A., \& Schuldt-Jensen, J. (2017). Smart Cities: A Case Study in Waste Monitoring and Management. Proceedings of the 50th Hawaii International Conference on System Sciences, 1392-1401.

Manyele, S. V. (2017). Analysis of Waste-Rock Transportation Process Performance in an OpenPit Mine Based on Statistical Analysis of Cycle Times Data. Engineering, 09(07), 649-679. https://doi.org/10.4236/eng.2017.97040

Marczak, H. (2016). Logistics of waste management in healthcare institutions. Journal of Ecological Engineering, 17(3), 113-118. https://doi.org/10.12911/22998993/63319

Miezah, K., Obiri-Danso, K., Kádár, Z., Fei-Baffoe, B., \& Mensah, M. Y. (2015). Municipal solid waste characterization and quantification as a measure towards effective waste management in Ghana. Waste Management, 46, 15-27. https://doi.org/10.1016/j.wasman.2015.09.009

NH, D., Vi, L. T. T., Mai, T. V. C., \& Matsui, Y. (2018). Scenario Analysis on Operation Efficiency for Waste Collection and Transport : A Case Study in Da Nang. Journal of Environmental and Social Sciences, 5(1), 1-13.

Paul, A. N., Ojekudo, \& Akpofure, N. (2015). Queuing theory and its application in waste management authority ( A focus on Lawma Igando dump site, Lagos state ). International Journal of Science and Research, 4(9), 1392-1400.

Raut, H. V, Nagne, A. D., \& Kale, K. V. (2015). Management of Food Waste by Using GIS Environment : A Review. International Journal of Computer Sciences and Engineering, 3(7), 144151.

Sivaraman, R., \& Bharti, S. (2017). Review Of Queuing And Reliability Model For Machine Interference And Repairing. IJEDR, 5(4), 774778 .

Tambe, E. B., Ayongwa, G. C., Ngwabie, N. M., \& Forbid, G. T. (2016). Characterisation of Municipal Solid Waste for Planning Sustainable Waste Management in Kumba Municipality South Western Cameroon. The Open Waste Management Journal, 9(1), 19-27. https://doi.org/10.2174/1876400201609010019

Zaveršnik, D., Tina, C., Grobin, K., \& Rosi, B. (2015). Optimization of Internal Logistics in a Waste Management Company With Queuing Theory. 2nd. Logistics International Conference., 284-289. 